\title{
大規模離散事象システムの分散状態フィードバック制御*
}

\author{
高井重昌 ${ }^{* *}$. 潮 俊 光 ${ }^{* *}$. 児玉 慎三**
}

\section{Decentralized State Feedback Control of Large-Scale Discrete Event Systems*}

\author{
Shigemasa TAKaI ${ }^{* *}$, Toshimitsu UShio ${ }^{* * *}$ and Shinzo Kodama**
}

\begin{abstract}
We consider decentralized state feedback control of large-scale discrete event systems consisting of several subsystems which operate concurrently. A (global) control specification is assumed to be given by a predicate. First, we study the relationship between the controllability with respect to entire systems and that with respect to subsystems, which is important for the synthesis of decentralized state feedbacks for large-scale discrete event systems. Next, we derive a necessary and sufficient condition for a decentralized state feedback to achieve the global optimal predicate achievable by a global state feedback. Especially, in the case that a control specification can be reduced to the simultaneous satisfaction of local control specifications, we can design each local state feedback based upon the corresponding local specification.
\end{abstract}

\section{1. 緒 言}

近年の離散事象システム ${ }^{1)}$ の大規模, 複雑化に伴い, その制御仕様もますます複雑となってきている．乙のた め, システム理論的観点から離散事象システムの制御理 論を構築することは重要な問題である ${ }^{2), 3)}$. 特に制御仕 様が状態の集合上の述語で与えられる場合, Ramadge とWonham によって提案されている状態フィードバッ ク制御) が有効である. 閉ループシステムに扔いて，与 えられた述語を満たす状態から可達なすべての状態です その述語が満たされるような状態フィードバックが存在 するとき, その述語は制御不変であるという4). しかし 制御不変性は, 閉ループシステムにおける可達な状態の 集合を特徴づけることができない ${ }^{5)}$. そこで述語の可制 御性という概念が提案され, 閉ループシステムにおける 可達な状態の集合が，述語 $Q$ を満たす状態の集合と等 しくなるような状態フィードバックが存在するための必 要十分条件は，Qが可制御であるということが証明され ている5).

* 原稿受付 1992.8.28

** 大阪大学 工学部 Osaka University ; 2-1 Yamadaoka, Suita-city, Osaka 565, JAPAN

*** 神戸女学院大学 家政学部

Kobe College ; 4-1 Okadayama, Nishinomiya-city, Hyogo 662, JAPAN

Key Words : ciscrete event system, large-scale system, decentralized control, state feedback, controllable predicate.
現実の離散事象システムの多くは, 複数の並行的に動 作するサブシステムにより構成されている.たとえば, FMS, 通信システム, コンピュータネットワークなどが その例として挙げられる。乙のような大規模離散事象シ ステムに対しては，設計や実装の容易さなどの点から， 一般に集中制御より屯分散制御が有効である. 制御仕様 が言語で与えられた場合のスーパバイザ制御 ${ }^{6)}$ において は, 大規模システムに対する分散制御が考察されている. つまり，グローバルな制御仕様が満たされるように，そ れぞれのローカルなスーパバイザがローカルな情報のみ に基づき対応するサブシステムを制御する方式が考察さ れている ${ }^{7,8)}$. また分散制御による大規模システムの安 定化についても考察されている ${ }^{9)}$. 一方, 状態フィード バック制御に抢いては, 制御仕様がローカルな制御仕様 の交わり，または結びで表わされる特別な場合の分散状 態フィードバックの構成法が, 制御不変性に基づき考察 されているにすぎない(10).

本論文では, 制御仕様が特別な仮定のない全体システ ムに関する述語で与えられる場合の分散状態フィードバッ ク制御において，特に閉ループシステムの可達な状態の 集合に関して考察する. まず 3 . では，述語の分離可能 性を定義し, 全体システムに関する述語の可制御性とサ ブシステムに関する可制御性との関係について考察する.

4. では, グローバルな状態フィードバックにより得られ る述語が，分散状態フィードバックによって屯得られる 
ための必要十分条件を求める. そして特に, 制御仕様が それぞれのサブシステムに対するローカルな制御仕様を 同時に満たすように与えられる場合, グローバルな状態 フィードバックにより得られる述語が, それぞれのロー カルな制御仕様のみを考慮して独立に構成された分散状 態フィードバックによっても得られるてとを示す. 最後 に 5.では, 得られた結果を簡単な生産システムの制御 に応用する.

\section{2. 準 備}

$G$ は (1) 式で表わされるオートマトン11) であるとす る.

$$
G=\left(X, \Sigma, \delta, x^{0}\right)
$$

ただし， $X$ は状態の集合， $x^{0}$ は初期状態， $\Sigma$ は事象の 有限集合, $\delta: \Sigma \times X \rightarrow X$ は状態遷移関数である. 一般 に $\delta$ は部分関数である. 以下 $\sigma \in \Sigma\llcorner x \in X$ に対して, $\delta(\sigma, x)$ が定義されているとき, $\delta(\sigma, x)$ ! 之書く. $\Sigma^{*}$ は空列 $\varepsilon$ を含む $\Sigma$ の要素からなるすべての有限系列の 集合とする. 遷移関数 $\delta$ を $\delta: \Sigma^{*} \times X \rightarrow X$ に次のよう 飞拡張する ${ }^{11)}$. 任意の $x \in X$ 亡任意の $w \in \Sigma^{*}, \sigma \in \Sigma$ に対して,

$$
\begin{aligned}
& \delta(\varepsilon, x)=x \\
& \delta(w \sigma, x)=\delta(\sigma, \delta(w, x))
\end{aligned}
$$

ただし， $x^{\prime}=\delta(w, x)$ かつ $\delta\left(\sigma, x^{\prime}\right)$ ! とする.

本論文では Ramadge-Wonham のモデルを考え $3^{2,4), 6)}$. すなわち，事象の集合 $\Sigma$ は制御できる事象の 集合 $\Sigma_{c}$ と制御できない事象の集合 $\Sigma_{u}$ に分割できる. ただし， $\Sigma=\Sigma_{c} \cup \Sigma_{u}, \Sigma_{c} \cap \Sigma_{u}=\phi$ である ${ }^{4), 6)} . \Sigma_{u}$ を含 む $\Sigma$ の部分集合を制御パターンといい, 制御パターン の集合を $\Gamma$ とおく.つまり,

$$
\Gamma=\left\{\gamma ; \Sigma_{u} \subseteq \gamma \subseteq \Sigma\right\}
$$

である. $G$ の各状態 $x \in X$ に対して制御パターン $\gamma \in \Gamma$ を与える写像 $f \in \Gamma^{X}$ を状態フィードバックという4). 状態フィードバック $f$ を施した閉ループシステム $G \mid f$ は,

$$
G \mid f=\left(X, \Sigma, \delta_{c f}, x_{0}\right)
$$

となる．ただし $\delta_{c f}: \Sigma \times X \rightarrow X$ は次式で定義される.

$$
\delta_{c f}(\sigma, x)= \begin{cases}\delta(\sigma, x), & \text { if } \sigma \in f(x) \\ \text { undefined, } & \text { otherwise }\end{cases}
$$

本論文では，制御仕様は状態の集合上の述語で与えら れているとする. $X$ 上の述語の集合を $\boldsymbol{P}=\{0,1\}^{X}$ と おく. 状態 $x \in X$ に打いて, 述語 $Q \in P$ が真であると き $Q(x)=1$, 偽であるとき $Q(x)=0$ と定義する. $\boldsymbol{P}$

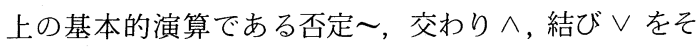

れぞれ次のように定義する. 任意の $x \in X$ に対して,

$$
\begin{aligned}
& \sim Q_{1}(x)=1 \Leftrightarrow Q_{1}(x)=0 \\
& \left(Q_{1} \wedge Q_{2}\right)(x)=1 \Leftrightarrow Q_{1}(x)=1 \text { and } Q_{2}(x)=1 \\
& Q_{1} \vee Q_{2}=\sim\left(\left(\sim Q_{1}\right) \wedge\left(\sim Q_{2}\right)\right)
\end{aligned}
$$

次に $P$ 上の半順序関係 $\leq$ を, $Q_{1} \wedge Q_{2}=Q_{1}$ のとき $Q_{1} \leq Q_{2}$ と定義する. そして各 $\sigma \in \Sigma$ に対して述語 $D_{\sigma}$ と $\boldsymbol{P}$ 上の変換 $w p_{\sigma}$ と $w l p_{\sigma}$ を次のように定義する ${ }^{4)}$.

$$
\begin{aligned}
& D_{\sigma}(x)= \begin{cases}1, & \text { if } \delta(\sigma, x) ! \\
0, & \text { otherwise }\end{cases} \\
& \begin{aligned}
w p_{\sigma}(Q) & (x) \\
& = \begin{cases}1, & \text { if } \delta(\sigma, x) ! \text { and } Q(\delta(\sigma, x))=1 \\
0, & \text { otherwise }\end{cases} \\
w l p_{\sigma}(Q) & =w p_{\sigma}(Q) \vee \sim D_{\sigma}
\end{aligned}
\end{aligned}
$$

述語 $Q \in \boldsymbol{P}$ が任意の $\sigma \in \Sigma_{u}$ に対して次式を満たすと き, $Q$ は $\Sigma_{u}$-不変であるという" .

$$
Q \leq w l p_{\sigma}(Q)
$$

さらに $Q\left(x^{0}\right)=1$ なる $Q \in P$ に対して, 述語 $\operatorname{Re}(G, Q) \in$ $P$ を次のように帰納的に定義する ${ }^{5)}$.

(1) $\operatorname{Re}(G, Q)\left(x^{0}\right)=1$

(2) $\operatorname{Re}(G, Q)(x)=1$ であり, $\delta(\sigma, x)$ ! なる $\sigma \in \Sigma$ に対して $Q(\delta(\sigma, x))=1$ ならば, $\operatorname{Re}(G, Q)$ $(\delta(\sigma, x))=1$ である.

(3) $\operatorname{Re}(G, Q)$ を満たすすべての状態は上の (1), (2) により得られる.

述語 $\operatorname{Re}(G, 1)$ および $\operatorname{Re}(G \mid f, 1)$ はそれぞれ $G$ およ び $G \mid f$ における可達な状態に打いてのみ真となる. 乙 こで述語 $1 \in P$ は次式で定義される.

$$
\mathbf{1}(x)=1, \quad \forall x \in X
$$

以後, 簡単のため $\operatorname{Re}(G):=\operatorname{Re}(G, 1), \operatorname{Re}(G \mid f):=$ $\operatorname{Re}(G \mid f, 1)$ と書く. $Q\left(x^{0}\right)=1$ なる述語 $Q \in \boldsymbol{P}$ が任意 の $\sigma \in \Sigma_{u}$ に対して次式を満たすとき, $Q$ は $G$ に関して 可制御であるという5).

$$
Q \leq \operatorname{Re}(G, Q) \wedge w l p_{\sigma}(Q)
$$

$\operatorname{Re}(G \mid f)=Q$ なる状態フィードバック $f \in \Gamma^{X}$ が存在 するための必要十分条件は， $Q$ が $G$ に関して可制御之 なることである5

$Q\left(x^{0}\right)=1$ なる述語 $Q \in P$ に対して述語の集合 $C(Q) \subseteq$ $P$ を次のように定義する.

$$
\begin{aligned}
C(Q)= & \left\{Q^{\prime} \in \boldsymbol{P} ; Q^{\prime} \leq Q \text { かつ } Q^{\prime} \text { は } G\right. \text { に関して } \\
& \text { 可制御 }\}
\end{aligned}
$$

$C(Q)$ は一般に空でないとは限らない. $C(Q)$ が空でな いための必要十分条件は, 次の条件 (C1) が成り立つこ 
とである.

(C 1) $\delta\left(w, x^{0}\right)$ ! なる任意の $w \in \Sigma_{u}^{*}$ に対して, $Q\left(\delta\left(w, x^{0}\right)\right)=1$ となる.

そして $C(Q)$ が空でないならば, $C(Q)$ の最大要素 $\sup C(Q)$ は常に存在する ${ }^{12)}$.

\section{3. 大規模離散事象システム}

本論文では, 互いに並行的に動作する複数のサブシス テム $G_{i}, i=1,2, \cdots, n$, からなる離散事象システム $G$ を考える. それぞれのサブシステムはオートマトン $G_{i}=$ $\left(X_{i}, \Sigma_{i}, \delta_{i}, x_{i}^{0}\right)$ で表わされるとする.ただし， $\Sigma_{i}=$ $\Sigma_{i c} \cup \Sigma_{i u}, \Sigma_{i c} \cap \Sigma_{i u}=\phi$ であり, 次の仮定を満たしてい るとする.

$$
\Sigma_{i u} \cap \Sigma_{j}=\phi, \quad \forall j \neq i
$$

この仮定は，制御できない事象によるサブシステム間の 同期はないということを意味する．それぞれの $\sigma \in \Sigma$ に対して, $\operatorname{In}(\sigma)$ を $\operatorname{In}(\sigma)=\left\{i ; \sigma \in \Sigma_{i}\right\}$ と定義する. このとき, 全体システム $G$ は次式で表わされる ${ }^{8)}$.

$$
G=\left(X, \Sigma, \delta, x^{0}\right)
$$

ただし， $X=X_{1} \times X_{2} \times \cdots \times X_{n}, \Sigma=\cup_{i=1}^{n} \Sigma_{i}\left(\Sigma_{c}=\right.$ $\cup_{i=1}^{n} \Sigma_{i c}$ かつ $\left.\Sigma_{u}=\cup_{i=1}^{n} \Sigma_{i u}\right), x^{0}=\left(x_{1}^{0}, x_{2}^{0}, \cdots, x_{n}^{0}\right)$ で あり, 部分関数 $\delta: \Sigma \times X \rightarrow X$ は次式で定義される.

$$
\begin{aligned}
& \delta\left(\sigma\left(x_{1}, x_{2}, \cdots, x_{n}\right)\right) \\
& \quad= \begin{cases}\left(x_{1}^{\prime}, x_{2}^{\prime}, \cdots, x_{n}^{\prime}\right), & \text { if } \delta_{i}\left(\sigma, x_{i}\right) ! \forall i \in \operatorname{In}(\sigma) \\
\text { undefined, } & \text { otherwise }\end{cases}
\end{aligned}
$$

ただし, $i \in \operatorname{In}(\sigma)$ ならば $x_{i}^{\prime}=\delta_{i}\left(\sigma, x_{i}\right)$ であり, $i \notin$ $\operatorname{In}(\sigma)$ ならば $x_{i}^{\prime}=x_{i}$ である. またてのとき $G=\|_{i=1}^{n} G_{i}$ 之書く.

全体システムGに扔いて，一つのサブシステムにし か属さない事象は，それぞれ非同期的に独立に生起する ことができる. 一方, 複数のサブシステムに属する共有 事象は，そのすべてのサブシステムに扔いて同時に生起 しなければならない。

写像 $T_{i}: X \rightarrow X_{i}, i=1,2, \cdots, n$, を次式で定義する. $T_{i}\left(\left(x_{1}, \cdots, x_{i}, \cdots, x_{n}\right)\right)=x_{i}$

つまり, $T_{i}(x)$ は $x$ の $i$ 番目の要素を表わす. $\boldsymbol{P}_{i}, i=$ $1,2, \cdots, n$, を $X_{i}$ 上のすべての述語の集合とする. 述 語 $Q \in \boldsymbol{P}$ に対して, 述語 $T_{i}(Q) \in \boldsymbol{P}_{i}(1 \leq i \leq n)$ を次 のように定義する.

$T_{i}(Q)\left(x_{i}\right)$

$= \begin{cases}1, & \text { if } T_{i}(x)=x_{i} \text { かつ } Q(x)=1 \text { なる } x \in X \text { が存在 } \\ 0, & \text { otherwise }\end{cases}$

$Q_{i}\left(x_{i}^{0}\right)=1$ なる $Q_{i} \in \boldsymbol{P}_{i}, i=1,2, \cdots, n$, に対して,
述語 $\|_{i=1}^{n} Q_{i} \in \boldsymbol{P}$ を次のように帰納的に定義する.

(1) $\|_{i=1}^{n} Q_{i}\left(x^{0}\right)=1$

(2) $\|_{i=1}^{n} Q_{i}(x)=1$ であり, $\delta(\sigma, x)$ ! なる $\sigma \in \Sigma$ 対し て $Q_{i}\left(T_{i}(\delta(\sigma x))\right)=1, i=1,2, \cdots, n$, ならば $\|_{i=1}^{n} Q_{i}(\delta(\sigma, x))=1$ である.

(3) $\|_{i=1}^{n} Q_{i}$ を満たすすべての状態は上の (1), (2) 飞 より得られる.

【定義 1】述語 $Q \in P$ に対して, $Q=\|_{i=1}^{n} Q_{i}$ なる述語 $Q_{i} \in \boldsymbol{P}_{i}, i=1,2, \cdots, n$, が存在するならば, $Q$ は $\left\{\boldsymbol{P}_{i}\right\}_{i=1}^{n}$ に関して分離可能であるという.

$\left\{\boldsymbol{P}_{i}\right\}_{i=1}^{n}$ に関して分離可能な述語 $Q \in \boldsymbol{P}$ に対して, $Q=\|_{i=1}^{n} Q_{i}$ ならば， $\left(Q_{1}, Q_{2}, \cdots, Q_{n}\right)$ は $Q$ の生成集合で あるという。一般にQの生成集合は複数存在する。 $Q$ のすべての生成集合の集合を $E(Q)$ で表わす.

【補題 1】 $\|_{i=1}^{n} Q_{i}(x)=1$ なる任意の $x \in X$ に対して, 次の（1）から（3）を満たす $x^{j} \in X, j=0,1, \cdots, m$, 之 $\sigma^{j} \in \Sigma, j=0,1, \cdots, m-1$, が存在する. ただし $x^{0}$ は $G$ の初期状態である.

(1) $\delta\left(\sigma^{j}, x^{j}\right)=x^{j+1}, \quad j=0,1, \cdots, m-1$

(2) $Q_{i}\left(T_{i}\left(x^{j}\right)\right)=1$, $i=1,2, \cdots, n, \quad j=0,1, \cdots, m$

(3) $x=x^{m}$

(証明) $\|_{i=1}^{n} Q_{i}(x)$ の定義より明らか.

【補題 2】述語 $Q \in \boldsymbol{P}$ は $\left\{\boldsymbol{P}_{i}\right\}_{i=1}^{n}$ 亿関して分離可能で あるとする. 乙のとき次式が成り立つ。

$$
Q=\operatorname{Re}(G, Q)
$$

(証明) $Q$ は分離可能であるから, $Q$ の生成集合 $\left(Q_{1}, Q_{2}, \cdots, Q_{n}\right) \in E(Q)$ が存在する. $\|_{i=1}^{n} Q_{i}$ の定義よ り, $Q\left(x^{0}\right)=\|_{i=1}^{n} Q_{i}\left(x^{0}\right)=1$ である. よって $\operatorname{Re}(G, Q)$ は定義できる. まず $Q \leq \operatorname{Re}(G, Q)$ を証明する. $Q(x)=$ 1 とすると, 補題 1 の (1), (2), (3) を満たす $x^{j} \in X$, $j=0,1, \cdots, m$, と $\sigma^{j} \in \Sigma, j=0,1, \cdots, m-1$, が存在 する. $\operatorname{Re}(G, Q)(x)=1$ を示すには, $Q\left(x^{j}\right)=1, j=$ $0,1, \cdots, m$, を示せば十分である. 乙れを州納法により証 明する. $Q\left(x^{0}\right)=1$ はすでに示した. 今, $j=k$ のとき, $Q\left(x^{k}\right)=1$ であると仮定する. つまり $\|_{i=1}^{n} Q_{i}\left(x^{k}\right)=1$ で あるとする. 補題 1 の (1), (2) より, $\delta\left(\sigma^{k}, x^{k}\right)=x^{k+1}$ かつ $Q_{i}\left(T_{i}\left(x^{k+1}\right)\right)=1, i=1,2, \cdots, n$, である. よって $\|_{i=1}^{n} Q_{i}$ の定義より, $\|_{i=1}^{n} Q_{i}\left(x^{k+1}\right)=1$ である. すなわち $Q\left(x^{k+1}\right)=1$ である. ゆえに帰納法により, $Q\left(x^{j}\right)=1$, $j=0,1, \cdots, m$, である.

逆に $\operatorname{Re}(G, Q)$ の定義より, 明らかに $\operatorname{Re}(G, Q) \leq Q$ である.

【系 1】述語 $Q \in \boldsymbol{P}$ は $\left\{\boldsymbol{P}_{i}\right\}_{i=1}^{n}$ に関して分離可能かつ $\Sigma_{u}$-不変であるとする. 乙のとき $Q$ は $G$ に関して可制 
御である.

（証明）補題 2 より明らか.

【補題 3】述語 $Q \in \boldsymbol{P}$ は $\left\{\boldsymbol{P}_{i}\right\}_{i=1}^{n}$ に関して分離可能で あるとする. 乙のとき $Q$ の任意の生成集合 $\left(Q_{1}, Q_{2}, \cdots\right.$, $\left.Q_{n}\right) \in E(Q)$ に対して, 次式が成り立つ.

$$
T_{i}(Q) \leq Q_{i}, \quad i=1,2, \cdots, n
$$

（証明） $T_{i}(Q)\left(x_{i}\right)=1(1 \leq i \leq n)$ なる任意の $x_{i} \in$ $X_{i}$ に対して, $T_{i}(x)=x_{i}$ かつ $Q(x)=1$ なる $x \in X$ が 存在する. $Q$ の任意の生成集合 $\left(Q_{1}, Q_{2}, \cdots, Q_{n}\right) \in E(Q)$ に対して，Q= $\|_{i=1}^{n} Q_{i}$ であるから, 補題 1 の (2), (3) より $Q_{i}\left(T_{i}(x)\right)=Q_{i}\left(x_{i}\right)=1$ である. ゆえに, (6) 式 が成り立つ.

【命題 1】述語 $Q \in \boldsymbol{P}$ は $\left\{\boldsymbol{P}_{i}\right\}_{i=1}^{n}$ に関して分離可能で あるとする. このとき次式が成り立つ.

$$
Q=\|_{i=1}^{n} T_{i}(Q)
$$

（証明）補題 2 の証明より $Q\left(x^{0}\right)=1$ である.よって 明らかに $T_{i}(Q)\left(x_{i}^{0}\right)=1$ である.よって $\|_{i=1}^{n} T_{i}(Q)$ は 定義できる. 補題 3 より，Qの任意の生成集合 $\left(Q_{1}\right.$, $\left.Q_{2}, \cdots, Q_{n}\right) \in E(Q)$ に対して, $T_{i}(Q) \leq Q_{i}, i=1,2, \cdots$, $n$, であるから, $\left\|_{i=1}^{n} T_{i}(Q) \leq\right\|_{i=1}^{n} Q_{i}=Q$ である.

逆に $Q \leq \|_{i=1}^{n} T_{i}(Q)$ を証明する. $Q(x)=1$ なる任意 の $x \in X$ に対して; 補題 2 より $\operatorname{Re}(G, Q)(x)=1$ であ る. このとき次の (4) から (6) を満たす $x^{j} \in X, j=0$, $1, \cdots, m, 之 \sigma^{j} \in \Sigma, j=0,1, \cdots, m-1$, が存在するて とが参考文献 5）に扣いて証明されている．ただし $x^{0}$ は $G$ の初期状態である.

(4) $\delta\left(\sigma^{j}, x^{j}\right)=x^{j+1}, \quad j=0,1, \cdots, m-1$

(5) $Q\left(x^{j}\right)=1, \quad j=0,1, \cdots, m$

(6) $x=x^{m}$

(5)より, $T_{i}(Q)\left(T_{i}\left(x^{j}\right)\right)=1, i=1,2, \cdots, n, j=0$, $1, \cdots, m$, である. よって $\|_{i=1}^{n} T_{i}(Q)$ の定義より, $\|_{i=1}^{n} T_{i}(Q)(x)=1$ である. ゆえに $Q \leq \|_{i=1}^{n} T_{i}(Q)$ が成 り立つ.

注意：任意の述語 $Q \in \boldsymbol{P}$ に対して $Q \geq \operatorname{Re}(G, Q)$ が 成立する. そして $Q=\operatorname{Re}(G, Q)$ ならば, $Q \leq \|_{i=1}^{n} T_{i}(Q)$ が常に成り立つが，それ以外の場合，一般には成り立た ない.

【命題 2】 $\operatorname{Re}(G)=\|_{i=1}^{n} \operatorname{Re}\left(G_{i}\right)$

(証明) 明らかに $\operatorname{Re}\left(G_{i}\right)\left(x_{i}^{0}\right)=1(1 \leq i \leq n)$ であ るから $\|_{i=1}^{n} \operatorname{Re}\left(G_{i}\right)$ は定義できる. まず $\|_{i=1}^{n} \operatorname{Re}\left(G_{i}\right) \leq$ $\operatorname{Re}(G)$ を証明する。 $\|_{i=1}^{n} \operatorname{Re}\left(G_{i}\right)(x)=1$ なる任意の $x \in X$ に対して, 補題 1 の (1), (3) より, $\delta\left(w, x^{0}\right)=x$ なる $w \in \Sigma^{*}$ が存在する. よって明らかに $\operatorname{Re}(G)(x)=$ 1 である.

逆に $\operatorname{Re}(G) \leq \|_{i=1}^{n} \operatorname{Re}\left(G_{i}\right)$ を証明する. $\operatorname{Re}(G)(x)=$
1 なる任意の $x \in X$ に対して, 補題1の (1), (3) を満 たす $x^{j} \in X, j=0,1,2, \cdots, m$, と $\sigma^{j} \in \Sigma, j=0,1, \cdots$, $m-1$, が存在する. $\|_{i=1}^{n} \operatorname{Re}\left(G_{i}\right)\left(x^{j}\right)=1, j=0,1, \cdots$, $m$, となることを帰納法により証明する. 定義より, $\|_{i=1}^{n} \operatorname{Re}\left(G_{i}\right)\left(x^{0}\right)=1$ である.今, $j=k$ のとき, $\|_{i=1}^{n} \operatorname{Re}\left(G_{i}\right)\left(x^{k}\right)=1$ であると仮定する. 乙のとき補題 1 の (2), (3) より $\operatorname{Re}\left(G_{i}\right)\left(T_{i}\left(x^{k}\right)\right)=1(1 \leq i \leq n)$ であ る. $i \in \operatorname{In}\left(\sigma^{k}\right)$ ならば, $T_{i}\left(x^{k+1}\right)=\delta_{i}\left(\sigma^{k}, T_{i}\left(x^{k}\right)\right)$ よ り, $\operatorname{Re}\left(G_{i}\right)\left(T_{i}\left(x^{k+1}\right)\right)=1$ である. $i \notin \operatorname{In}\left(\sigma^{k}\right)$ ならば, $T_{i}\left(x^{k+1}\right)=T_{i}\left(x^{k}\right)$ であるから, $\operatorname{Re}\left(G_{i}\right)\left(T_{i}\left(x^{k+1}\right)\right)=1$ である.よって $\|_{i=1}^{n} \operatorname{Re}\left(G_{i}\right)\left(x^{k+1}\right)=1$ である. ゆえに 㷌納法により $\|_{i=1}^{n} \operatorname{Re}\left(G_{i}\right)(x)=1$ である.

以下の命題は, 次の章で述べる分散状態フィードバッ クの構成に関して重要である.

【命題 3】述語 $Q \in P$ は $G$ に関して可制御であるとす る. このときそれぞれ $i(1 \leq i \leq n)$ において, $T_{i}(Q) \in$ $\boldsymbol{P}_{i}$ は $G_{i}$ に関して可制御である.

証明は付録 1 亿示す.

【命題 4】それぞれ $i(1 \leq i \leq n)$ ておいて, $Q_{i} \in \boldsymbol{P}_{i}$ は $G_{i}$ に関して可制御であるとする. 乙のとき $\|_{i=1}^{n} Q_{i} \in P$ は $G$ に関して可制御である.

証明は付録 2 亿示す.

【命題 5】述語 $Q \in \boldsymbol{P}$ は $\left\{\boldsymbol{P}_{i}\right\}_{i=1}^{n}$ に関して分離可能 であり, $C(Q)$ は空でないとする. このとき任意の $Q$ の生成集合 $\left(Q_{1}, Q_{2}, \cdots, Q_{n}\right) \in E(Q)$ に対して, $T_{i}(\sup C(Q)) \in C_{i}\left(Q_{i}\right), i=1,2, \cdots, n$, である. ただ L,

$$
\begin{aligned}
C_{i}\left(Q_{i}\right)= & \left\{Q_{i}^{\prime} \in P_{i} ; Q_{i}^{\prime} \leq Q_{i} \text { かつ } Q_{i}^{\prime} \text { は } G_{i}\right. \text { に関して } \\
& \text { 可制御 }\}
\end{aligned}
$$

である。

（証明） $C(Q)$ は空でないので, $\sup C(Q)$ が存在す る. 命題 3 より, $T_{i}(\sup C(Q)), i=1,2, \cdots, n$, は $G_{i}$ 飞関して可制御である. そして $\sup C(Q) \leq Q$ より, $T_{i}(\sup C(Q)) \leq T_{i}(Q), i=1,2, \cdots, n$, である. ま た補題 3 より，Qの任意の生成集合 $\left(Q_{1}, Q_{2}, \cdots, Q_{n}\right) \in$ $E(Q)$ に対して, $T_{i}(Q) \leq Q_{i}, i=1,2, \cdots, n$, である. ゆえに $T_{i}(\sup C(Q)) \in C_{i}\left(Q_{i}\right)$ となる.

\section{4. 大規模離散事象システムの分散制御}

全体システム $G$ に対して, 制御仕様として $Q\left(x^{0}\right)=1$ を満たす述語 $Q \in \boldsymbol{P}$ が与えられているとする. 本章で は， $Q$ は条件 (C 1) を満たしている，すなわち $C(Q)$ は 空でないと仮定する. このとき，

$$
K:=\operatorname{Re}(G \mid f)=\sup C(Q)
$$

なるグローバルな状態フィードバック $f \in \Gamma^{X}$ が存在す 
る. $\operatorname{Re}\left(G \mid f^{\prime}\right) \leq Q$ なる任意のグローバルな状態フィ 一ドバック $f^{\prime} \in \Gamma^{X}$ に対して, $\operatorname{Re}\left(G \mid f^{\prime}\right) \leq \sup C(Q)$ となるという意味で, $K$ はグローバルな状態フィード バックにより得られる最適な述語である ${ }^{12)}$. 本論文では, グローバルな状態フィードバックではなく，それぞれの サブシステム $G_{i}$ がローカルな状態フィードバック $f_{i}$ に よってのみ制御されるような分散状態フィードバックを 考える.それぞれのローカルな状態フィードバック $f_{i}$ に対して， $G_{i}$ の状態のみが観測可能であり， $\sum_{i c}$ に属す る事象のみが制御可能である. ローカルな状態フィード バックの組 $\left\{f_{i}\right\}_{i=1}^{n}$ を分散状態フィードバックと呼ぶ. 分散状態フィードバックを施した全体の閉ループシステ ム $G \mid\left\{f_{i}\right\}_{i=1}^{n}$ は $G\left|\left\{f_{i}\right\}_{i=1}^{n}=\|_{i=1}^{n} G_{i}\right| f_{i}$ と書ける. ただ し一般に $\operatorname{Re}\left(G \mid\left\{f_{i}\right\}_{i=1}^{n}\right) \leq \|_{i=1}^{n} \operatorname{Re}\left(G_{i} \mid f_{i}\right)$ である. （証明は付録 3 を参照されたい. ) また簡単のため $K_{\text {loc }}:=$ $\operatorname{Re}\left(G \mid\left\{f_{i}\right\}_{i=1}^{n}\right)$ と書く.

ローカルな状態フィードバック $f_{i}(1 \leq i \leq n)$ が次 の条件 $(\mathrm{C} 2)$ を満たしているとき, $f_{i}$ はbalanced であ るという5).

（C2）任意の $x_{i}, x_{i}^{\prime} \in X_{i}$ と任意の $\sigma_{i} \in \Sigma_{i}$ に対して, $\operatorname{Re}\left(G_{i} \mid f_{i}\right)\left(x_{i}\right)=\operatorname{Re}\left(G_{i} \mid f_{i}\right)\left(x_{i}^{\prime}\right)=1$ かつ $\delta_{i}\left(\sigma_{i}, x_{i}\right)=x_{i}^{\prime}$ ならば, $\sigma_{i} \in f_{i}\left(x_{i}\right)$ である.

そして各 $f_{i}, i=1,2, \cdots, n$, が balanced であるとき, 分散状態フィードバック $\left\{f_{i}\right\}_{i=1}^{n}$ は balanced であると いう. balancedな分散状態フィードバック $\left\{f_{i}\right\}_{i=1}^{n}$ に対 して, 次の命題が得られる.

【命題 6】balanced な分散状態フィードバック $\left\{f_{i}\right\}_{i=1}^{n}$ に対して, 次式が成り立つ.

$$
\operatorname{Re}\left(G \mid\left\{f_{i}\right\}_{i=1}^{n}\right)=\|_{i=1}^{n} \operatorname{Re}\left(G_{i} \mid f_{i}\right)
$$

証明は付録 3 亿示す. 命題 $\mathbf{6}$ より $\left\{f_{i}\right\}_{i=1}^{n}$ が balanced な らば， $K_{l o c}$ は各サブシステムに関する述語 $\operatorname{Re}\left(G_{i} \mid f_{i}\right)$ によって表わされる．任意のローカルな状態フィードバッ ク $f_{i}^{\prime}(1 \leq i \leq n)$ に対して,

$$
\operatorname{Re}\left(G_{i} \mid f_{i}\right)=\operatorname{Re}\left(G_{i} \mid f_{i}^{\prime}\right)
$$

なる balanced な状態フィードバック $f_{i}$ が存在する5). よって以下，本論文ではbalanced な分散状態フィード バックのみを考える.

次の結果は, 分散制御が集中制御より一般的に劣るこ とを示している.

【命題 7】 $K_{\text {loc }} \leq Q$ なる balanced な分散状態フィー ドバック $\left\{f_{i}\right\}_{i=1}^{n}$ が存在するとする. 乙のとき $K_{l o c} \leq K$ が成り立つ.

（証明） 任意の balanced な分散状態フィードバック $\left\{f_{i}\right\}_{i=1}^{n}$ に対して, $\operatorname{Re}\left(G_{i} \mid f_{i}\right), i=1,2, \cdots, n$, は $G_{i}$ に
関して可制御である. よって命題 4 と命題 6 より， $K_{l o c}$ は $G$ に関して可制御である. ゆえに $K_{l o c} \leq Q$ であるか ら, $K_{l o c} \leq \sup C(Q)=K$ である.

注意: 明らかに命題 7 は $\left\{f_{i}\right\}_{i=1}^{n}$ が balanced でない 場合においても成立する.

次に分散状態フィードバックにより, 最適なグローバ ルな述語 $K$ が得られるための必要十分条件を示す.

【定理 1】 $K_{l o c}=K$ なる balanced な分散状態フィ 一ドバック $\left\{f_{i}\right\}_{i=1}^{n}$ が存在するための必要十分条件は, $K$ が $\left\{\boldsymbol{P}_{i}\right\}_{i=1}^{n}$ に関して分離可能となることである.

（証明）まず必要性を証明する. 命題 6 より, $K_{l o c}=$ $\|_{i=1}^{n} \operatorname{Re}\left(G_{i} \mid f_{i}\right)=K$ であるから, $K$ は $\left\{\boldsymbol{P}_{i}\right\}_{i=1}^{n}$ に関し て分離可能である.

次に十分性を証明する. $K$ は $\left\{\boldsymbol{P}_{i}\right\}_{i=1}^{n}$ に関して分離可 能であるから, 命題 1 より,

$$
K=\|_{i=1}^{n} T_{i}(K)
$$

である. また $K$ は $G$ に関して可制御であるから, 命題 3 より, $T_{i}(K), i=1,2, \cdots, n$, は $G_{i}$ に関して可制御で ある. よって $\operatorname{Re}\left(G_{i} \mid f_{i}\right)=T_{i}(K)$ なる balanced な分 散状態フィードバック $\left\{f_{i}\right\}_{i=1}^{n}$ が存在する. この $\left\{f_{i}\right\}_{i=1}^{n}$ に対して,

$$
\begin{aligned}
K_{l o c} & =\|_{i=1}^{n} \operatorname{Re}\left(G_{i} \mid f_{i}\right) \\
& =\|_{i=1}^{n} T_{i}(K) \\
& =K
\end{aligned}
$$

となる。

定理 1 は述語 $K(=\sup C(Q))$ に関する条件となっ ている，一般に全体システム $G$ の状態数は，サブシステ 么の数に関して指数的に増加する. 乙のため, 実際には $K$ の計算が困難な場合がある.よって $K$ を計算するて となく, $K_{l o c}=K$ なる分散状態フィードバックが構成 できる条件を求めることは重要である.

【定理 2】述語 $Q \in \boldsymbol{P}$ は $\left\{\boldsymbol{P}_{i}\right\}_{i=1}^{n}$ に関して分離可能で あり，( $\left.Q_{1}, Q_{2}, \cdots, Q_{n}\right)$ は $Q$ の生成集合であるとする. このとき次式を満たす balanced な分散状態フィードバッ ク $\left\{f_{i}\right\}_{i=1}^{n}$ が存在する.

$$
\begin{aligned}
& \operatorname{Re}\left(G_{i} \mid f_{i}\right)=\sup C_{i}\left(Q_{i}\right), \quad i=1,2, \cdots, n \text { (10) } \\
& K_{l o c}=K
\end{aligned}
$$

証明は付録 4 亿示す. 定理 2 と命題 1 より, $Q$ が $\left\{\boldsymbol{P}_{i}\right\}_{i=1}^{n}$ に関して分離可能であるとき, $K_{l o c}=K$ なる分散状態 フィードバック $\left\{f_{i}\right\}_{i=1}^{n}$ を構成するために，K を計算す る代わりに $T_{i}(Q) と \sup C_{i}\left(T_{i}(Q)\right), i=1,2, \cdots, n$, を計算すればよいことがわかる.

これまでは制御仕様は全体システム $G$ の振る舞いに関 して与えられると仮定してきた. 次に制御仕様がそれぞれ 
のサブシステムに対するローカルな制御仕様を同時に満 たすように与えられる場合を考える． $Q_{i}, i=1,2, \cdots, n$, をサブシステム $G_{i}$ に対するローカルな制御仕様とする. そしてグローバルな制御仕様 $Q$ は次式で与えられると する.

$$
Q=\|_{i=1}^{n} Q_{i}
$$

このとき $\left(Q_{1}, Q_{2}, \cdots, Q_{n}\right)$ は $Q$ の生成集合となるので, 定理 2 より次の結果が得られる.

【定理 3】述語 $Q \in \boldsymbol{P}$ は (12) 式で与えられていると する．乙のとき次式を満たすbalanced な分散状態つィ ードバック $\left\{f_{i}\right\}_{i=1}^{n}$ が存在する.

$$
\begin{aligned}
& \operatorname{Re}\left(G_{i} \mid f_{i}\right)=\sup C_{i}\left(Q_{i}\right), i=1,2, \cdots, n \\
& K_{l o c}=K
\end{aligned}
$$

定理 3 は，制御仕様がそれぞれのサブシステムに対す るローカルな制御仕様を同時に満たすように与えられる 場合, それぞれのローカルな制御仕様 $Q_{i}$ 対して (13) 式 を満たすローカルな状態フィードバック $f_{i}$ を独立に構 成することにより, 最適なグローバルな述語 $K$ が得ら れることを示している.

\section{5. 例 題}

本章では, Fig. 1 亿示す二つの機械 $G_{1}, G_{2}$ からなる 生産システム $G$ を考える. $G_{1}, G_{2}$ はそれぞれ Fig. 2 の オートマトンで表わされる. ただし， $x^{0}=\left(I_{1}, I_{2}\right), \Sigma_{1 c}=$ $\{a, b\}, \Sigma_{1 u}=\phi, \Sigma_{2 c}=\{b\}, \Sigma_{2 u}=\{c\}$ であり, $b$ は共有 事象である. 事象 $a, b, c$ の意味は次のようになる.

$a:$ パーツの $G_{1}$ での加工開始.

$b:$ パーツの $G_{1}$ での加工が終了し, $G_{2}$ での加工開始.

$c:$ パーツの $G_{2}$ での加工が終了.

今, $G_{1}, G_{2}$ それぞれで加工できるパーツは高々 1 個と

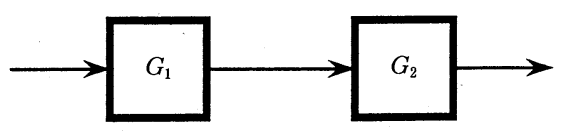

Fig. 1 A simple manufacturing system
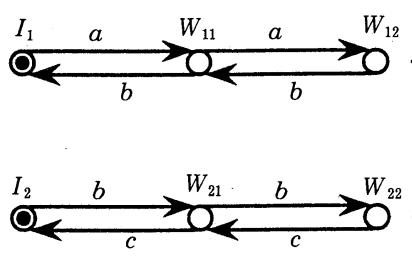

Fig. 2 Subsystems of the example (The double circles are the initial states)
なる制御を考える。乙のとき全体システム $G$ に対する 制御仕様は次のような述語 $Q$ で表わされる.

$Q(x)$

$= \begin{cases}1, & \text { if } x \in\left\{\left(I_{1}, I_{2}\right),\left(I_{1}, W_{21}\right),\left(W_{11}, I_{2}\right),\left(W_{11}, W_{21}\right)\right\} \\ 0, & \text { otherwise }\end{cases}$

$Q$ が $G$ に関して可制御であることは容易に確かめら れる.つまり,

$$
K:=\sup C(Q)=Q
$$

である. また $Q=\|_{i=1}^{2} T_{i}(Q)$ となるので, $Q$ は $\left\{\boldsymbol{P}_{i}\right\}_{i=1}^{2}$ に関して分離可能である. よって定理 1 より,

$$
K_{l o c}:=\operatorname{Re}\left(G \mid\left\{f_{i}\right\}_{i=1}^{2}\right)=K
$$

なる balanced な分散状態フィードバック $\left\{f_{i}\right\}_{i=1}^{2}$ が存在 し，それは次式で得られる.

$$
\begin{aligned}
& f_{1}\left(x_{1}\right)= \begin{cases}\{b\}, & \text { if } x_{1}=W_{11} \\
\{a, b\}, & \text { otherwise }\end{cases} \\
& f_{2}\left(x_{2}\right)= \begin{cases}\{c\}, & \text { if } x_{2}=W_{21} \\
\{b, c\}, & \text { otherwise }\end{cases}
\end{aligned}
$$

\section{6. 結 論}

本論文では, 大規模離散事象システムの分散状態フィー ドバック制御について考察した. まずグローバルな状態 フィードバックにより得られる最適な述語が, 分散状態 フィードバックによっても得られるための必要十分条件 を導出した．特に制御仕様がそれぞれのサブシステムに 対するローカルな制御仕様を同時に満たすように与えら れる場合, それぞれのローカルな制御仕様のみを考慮して 独立に構成されたローカルな状態フィードバックの組に より, 最適なグローバルな述語が得られることを示した。

一般に, 最適なグローバルな述語が得られる分散状態 フィードバックは複数存在する. これらの分散状態フィ 一ドバックの性質を考察することは今後の課題である.

また, 分離可能な述語は非常に望ましい性質を持つの で，与えられた述語に対して，その最大可制御かつ分離 可能な部分述語の構成法を明らかにすることも, 今後の 重要な検討課題である.

\section{参 考 文 献}

1) P. Varaiya and A. B. Kurzhanski : Discrete Event Systems : Models and Applications; Lecture Notes in Control and Information Sciences, Vol. 103, Springer (1988)

2) P. J. Ramadge and W. M. Wonham: The Control of Discrete Event Systems; Proc. IEEE, Vol. 77, No. 1, pp. 81 98 (1989)

3) 潮: 離散事象システムにおける制御問題とスーパバイザ; システム/制御/情報, Vol. 34, No. 9, pp. 531〜538 (1990) 
4) P. J. Ramadge and W. M. Wonham : Modular Feedback Logic for Discrete Event Systems; SIAM J. Contr. Optimiz., Vol. 25, No. 5, pp. 1202 1218 (1987)

5) Y.Li and W.M. Wonham : Controllability and Observability in the State Feedback Control of Discrete-Event Systems ; Proc. 27 th IEEE CDC, pp. 203 208 (1988)

6) P.J. Ramadge and W. M. Wonham : Supervisory Control of a Class of Discrete-Event Processes; SIAM J. Contr. Optimiz., Vol. 25, No. 1, pp. 206 230 (1987)

7) F. Lin and W. M. Wonham : Decentralized Control and Coordination of Discrete-Event Systems with Partial Observation ; IEEE Trans. Automat. Contr., Vol. 35, No. 12, pp. $1330 \sim 1337$ (1990)

8) Y. Willner and M. Heymann : Supervisory Control of Concurrent Discrete-Event Systems ; Int. J. Control, Vol. 54, No. 5, pp. 1143〜1169 (1991)

9) 高井, 潮 : 分散状態フィードバックによる離散事象システム の安定化; 電子情報通信学会論文誌 A 分冊, Vol. J 75-A, No. 3, pp. 543 551 (1992)

10) W. Lu and Y. Chen : Structuralized Control Logic for Discrete Event Systems ; Proc. International Conference on Control and Application, pp. WP-4-4 1 6 (1989)

11) J. E. Hopcroft and J. D. Ullman : Introduction to Automata Theory, Language, and Computation, AddisonWesley (1979)

12) Y. Li and W. M. Wonham : A State-Variable Approach to the Modeling and Control of Discrete-Event Systems ; Proc. 26 th Annual Allerton Conf. on Communication, Control and Computing, pp. 1140 1149 (1988)

\section{付 録}

\section{付録 1 命題 3 の証明}

$Q$ は $G$ に関して可制御であるから，任意の $\sigma \in \Sigma_{u}$ に 対して,

$$
Q \leq \operatorname{Re}(G, Q) \wedge w l p_{\sigma}(Q)
$$

である. $Q\left(x^{0}\right)=1$ より $T_{i}(Q)\left(x_{i}^{0}\right)=1$ であるので, $\operatorname{Re}\left(G_{i}, T_{i}(Q)\right)$ は定義できる.

まず $T_{i}(Q) \leq \operatorname{Re}\left(G_{i}, T_{i}(Q)\right)(1 \leq i \leq n)$ を証明す る. $T_{i}(Q)\left(x_{i}\right)=1$ なる任意の $x_{i} \in X_{i}$ に対して, $T_{i}(x)=x_{i}, Q(x)=1$ なる $x \in X$ が存在する. ての $x \in X$ に対して $\operatorname{Re}(G, Q)(x)=1$ である. よって命題 1 の証明中の (4) から (6) を満たす $x^{j} \in X, j=0,1, \cdots$, $m, 之 \sigma^{j} \in \Sigma, j=0,1, \cdots, m-1$, が存在する. 簡単の ため, $T_{i}\left(x^{j}\right)=x_{i}^{j}, i=1,2, \cdots, n, j=0,1, \cdots, m$, 之 打く. $\operatorname{Re}\left(G_{i}, T_{i}(Q)\right)\left(x_{i}^{j}\right)=1, j=0,1, \cdots, m$, を州 納法により証明する. $\operatorname{Re}\left(G_{i}, T_{i}(Q)\right)$ の定義より, $\operatorname{Re}\left(G_{i}, T_{i}(Q)\right)\left(x_{i}^{0}\right)=1$ である. 今, $j=k$ のとき, $\operatorname{Re}\left(G_{i}, T_{i}(Q)\right)\left(x_{i}^{k}\right)=1$ であると仮定する. $i \in \operatorname{In}\left(\sigma^{k}\right)$ ならば $x_{i}^{k+1}=\delta_{i}\left(\sigma^{k}, x_{i}^{k}\right)$ である。また（5）より $Q\left(x^{k+1}\right)=1$ であるから, $T_{i}(Q)\left(x_{i}^{k+1}\right)=1$ である.

よって $\operatorname{Re}\left(G_{i}, T_{i}(Q)\right)$ の定義より, $\operatorname{Re}\left(G_{i}, T_{i}(Q)\right)$ $\left(x_{i}^{k+1}\right)=1$ である. 一方, $i \notin \operatorname{In}\left(\sigma^{k}\right)$ ならば $x_{i}^{k+1}=x_{i}^{k}$ であるから, $\operatorname{Re}\left(G_{i}, T_{i}(Q)\right)\left(x_{i}^{k+1}\right)=1$ である.よっ て帰納法により, $\operatorname{Re}\left(G_{i}, T_{i}(Q)\right)\left(x_{i}^{m}\right)=1$ である. さ
らに(6)より, $x_{i}=T_{i}(x)=T_{i}\left(x^{m}\right)=x_{i}^{m}$ であるから, $\operatorname{Re}\left(G_{i}, T_{i}(Q)\right)\left(x_{i}\right)=1$ である.ゆえに $T_{i}(Q) \leq$ $\operatorname{Re}\left(G_{i}, T_{i}(Q)\right)(1 \leq i \leq n)$ が成り立つ.

次に任意の $\sigma \in \Sigma_{i u}(1 \leq i \leq n)$ に対して,

$$
T_{i}(Q) \leq w l p_{\sigma}\left(T_{i}(Q)\right)
$$

となることを背理法により証明する. $T_{i}(Q)\left(x_{i}\right)=1$, $w l p_{\sigma}\left(T_{i}(Q)\right)\left(x_{i}\right)=0$ なる $x_{i} \in X_{i}, \sigma \in \Sigma_{i u}$ が存在す ると仮定する. 乙のとき $T_{i}(x)=x_{i}, Q(x)=1$ なる $x \in$ $X$ が存在する， $\sigma \in \Sigma_{i u}$ であるから,$\sigma \notin \Sigma_{j}(\forall j \neq i)$

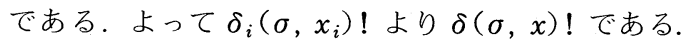
$\delta(\sigma, x)=x^{\prime}$ とすると, $T_{i}\left(x^{\prime}\right)=\delta_{i}\left(\sigma, x_{i}\right)$ であり, $w l p_{\sigma}\left(T_{i}(Q)\right)\left(x_{i}\right)=0$ より, $T_{i}(Q)\left(T_{i}\left(x^{\prime}\right)\right)=0$ であ る. よって $Q\left(x^{\prime}\right)=0$ である. すなわち $w l p_{\sigma}(Q)(x)=$ 0 であり，乙れは $Q$ の可制御性に矛盾する.

ゆえに $T_{i}(Q)$ は $G_{i}$ に関して可制御である.

\section{付録 2 命題 4 の証明}

$Q=\|_{i=1}^{n} Q_{i}$ 之おく. $Q$ は分離可能であるから，系 1 よ り $Q$ が $\Sigma_{u}$-不変であることを示せば十分である. 今, $Q(x)=1, w l p_{\sigma}(Q)(x)=0$ なる $x \in X, \sigma \in \Sigma_{u}$ が存 在すると仮定する. $\sigma \in \Sigma_{u}$ に対して, $\sigma \in \Sigma_{j}, \sigma \notin$ $\Sigma_{i}(\forall i \neq j)$ なる $j(1 \leq j \leq n)$ が存在する. $Q(x)=$ $\|_{i=1}^{n} Q_{i}(x)=1$ より, $Q_{i}\left(T_{i}(x)\right)=1, i=1,2, \cdots, n$, で ある. $\delta(\sigma, x)=x^{\prime}$ とすると, $i \neq j$ ならば $T_{i}\left(x^{\prime}\right)=$ $T_{i}(x)$ より $Q_{i}\left(T_{i}\left(x^{\prime}\right)\right)=1$ である. 一方, $Q_{j}$ の可制 御性より $w l p_{o}\left(Q_{j}\right)\left(T_{j}(x)\right)=1$ である. $T_{j}\left(x^{\prime}\right)=$ $\delta_{j}\left(\sigma, T_{j}(x)\right)$ より, $Q_{j}\left(T_{j}\left(x^{\prime}\right)\right)=1$ である. したがっ て $\|_{i=1}^{n} Q_{i}\left(x^{\prime}\right)=1$, すなわち $Q\left(x^{\prime}\right)=1$ となり, これは $w l p_{\sigma}(Q)(x)=0$ に矛盾する.

\section{付録 3 命題 6 の証明}

まず任意の分散状態フィードバック $\left\{f_{i}\right\}_{i=1}^{n}$ に対して, $\operatorname{Re}\left(G, \mid\left\{f_{i}\right\}_{i=1}^{n}\right) \leq \|_{i=1}^{n} \operatorname{Re}\left(G_{i} \mid f_{i}\right)$ となるととを証明す る. $\operatorname{Re}\left(G \mid\left\{f_{i}\right\}_{i=1}^{n}\right)(x)=1$ なる任意の $x \in X$ に対して, 次の (7) から（9）を満たす $x^{j} \in X, j=0,1, \cdots, m$, と $\sigma^{j} \in \Sigma, j=0,1, \cdots, m-1$, が存在する. ただし $x^{0}$ は $G$ の初期状態である.

(7) $\delta\left(\sigma^{j}, x^{j}\right)=x^{j+1}, \quad j=0,1, \cdots, m-1$

(8) $x=x^{m}$

(9) $\sigma^{j} \in f_{i}\left(T_{i}\left(x^{j}\right)\right), \quad \forall i \in \operatorname{In}\left(\sigma^{j}\right)$, $j=0,1, \cdots, m-1$

$\|_{i=1}^{n} \operatorname{Re}\left(G_{i} \mid f_{i}\right)\left(x^{j}\right)=1, j=0,1, \cdots, m$, を帰納法に より証明する. 定義より $\|_{i=1}^{n} \operatorname{Re}\left(G_{i} \mid f_{i}\right)\left(x^{0}\right)=1$ であ る. 今, $j=k$ のとき, \|\|$_{i=1}^{n} \operatorname{Re}\left(G_{i} \mid f_{i}\right)\left(x^{k}\right)=1$ である と仮定する. 乙のとき $\operatorname{Re}\left(G_{i} \mid f_{i}\right)\left(T_{i}\left(x^{k}\right)\right)=1, i=1$, $2, \cdots, n$, である. $i \in \operatorname{In}\left(\sigma^{k}\right)$ ならば, $\delta_{i}\left(\sigma^{k}, T_{i}\left(x^{k}\right)\right)=$ $T_{i}\left(x^{k+1}\right)$ であり, (9)より $\sigma^{k} \in f_{i}\left(T_{i}\left(x^{k}\right)\right)$ であるか ら, $\operatorname{Re}\left(G_{i} \mid f_{i}\right)\left(T_{i}\left(x^{k+1}\right)\right)=1$ である. $i \notin \operatorname{In}\left(\sigma^{k}\right)$ 
ならば, $T_{i}\left(x^{k+1}\right)=T_{i}\left(x^{k}\right)$ であるから, $\operatorname{Re}\left(G_{i} \mid f_{i}\right)$ $\left(T_{i}\left(x^{k+1}\right)\right)=1$ である. よって $\|_{i=1}^{n} \operatorname{Re}\left(G_{i} \mid f_{i}\right)\left(x^{k+1}\right)=$ 1 である.

次に $\left\{f_{i}\right\}_{i=1}^{n}$ が balanced のときには, $\|_{i=1}^{n} \operatorname{Re}\left(G_{i} \mid f_{i}\right) \leq$ $\operatorname{Re}\left(G \mid\left\{f_{i}\right\}_{i=1}^{n}\right)$ となるととを証明する. 補題 1 より $\|_{i=1}^{n}$ $\operatorname{Re}\left(G_{i} \mid f_{i}\right)(x)=1$ なる任意の $x \in X$ に対して, 次の (10) から（12）を満たす $x^{j} \in X, j=0,1, \cdots, m$, と $\sigma^{j} \in \Sigma, j=0,1, \cdots, m-1$, が存在する. ただし $x^{0}$ は $G$ の初期状態である.

(10) $\delta\left(\sigma^{j}, x^{j}\right)=x^{j+1}, \quad j=0,1, \cdots, m-1$

(11) $\operatorname{Re}\left(G_{i} \mid f_{i}\right)\left(T_{i}\left(x^{j}\right)\right)=1, \quad i=1,2, \cdots, n$, $j=0,1, \cdots, m$

(12) $x=x^{m}$

$\operatorname{Re}\left(G \mid\left\{f_{i}\right\}_{i=1}^{n}\right)(x)=1$ を示すには, 各 $\sigma^{j}, j=0,1, \cdots$, $m-1$, に対して,

$$
\sigma^{j} \in f_{i}\left(T_{i}\left(x^{j}\right)\right), \quad \forall i \in \operatorname{In}\left(\sigma^{j}\right)
$$

となることを示せば十分である. $\sigma^{j} \in \Sigma_{u}$ ならば $\sigma^{j} \in$ $\Sigma_{i}$ なる $i$ に対して, $\sigma^{j} \in f_{i}\left(T_{i}\left(x^{j}\right)\right)$ が成り立つ. $\sigma^{j} \in \Sigma_{c}$ ならば， $i \in I_{n}\left(\sigma^{j}\right)$ なる $i$ に対して, (11)よ り $\operatorname{Re}\left(G_{i} \mid f_{i}\right)\left(T_{i}\left(x^{j}\right)\right)=\operatorname{Re}\left(G_{i} \mid f_{i}\right)\left(T_{i}\left(x^{j+1}\right)\right)=1$ であり, $\delta_{i}\left(\sigma^{j}, T_{i}\left(x^{j}\right)\right)=T_{i}\left(x^{j+1}\right)$ であるから, 条件 (C2) より $\sigma^{j} \in f_{i}\left(T_{i}\left(x^{j}\right)\right)$ である. Фえに $\operatorname{Re}(G \mid$ $\left.\left\{f_{i}\right\}_{i=1}^{n}\right)(x)=1$ である.

\section{付録 4 定理 2 の証明}

【補題 A1】述語 $Q^{\prime} \in \boldsymbol{P}$ は $G$ 亿関して可制御である とする. このとき次式が成り立つ.

$$
Q^{\prime} \leq \|_{i=1}^{n} T_{i}\left(Q^{\prime}\right)
$$

(証明) $Q^{\prime}$ は $G$ 亿関して可制御であるから, $Q^{\prime}(x)=$ 1 なる任意の $x \in X$ に対して, $\operatorname{Re}(G, Q)(x)=1$ とな る. よって命題 1 の $Q \leq \|_{i=1}^{n} T_{i}(Q)$ の証明と同様にし て (A1) 式が証明できる.

$Q$ は $\left\{\boldsymbol{P}_{i}\right\}_{i=1}^{n}$ に関して分離可能であり, $C(Q)$ は空で ないので, 命題 $\mathbf{5}$ より $C_{i}\left(Q_{i}\right), i=1,2, \cdots, n$, 屯空で はない. よって各 $i(1 \leq i \leq n)$ に対して $\sup C_{i}\left(Q_{i}\right)$ が存在し, $\sup C_{i}\left(Q_{i}\right)$ の可制御性より, $\operatorname{Re}\left(G_{i} \mid f_{i}\right)=$ $\sup C_{i}\left(Q_{i}\right)$ なる balanced な分散状態フィードバック $\left\{f_{i}\right\}_{i=1}^{n}$ が存在する.

まず $K_{l o c} \leq K$ を証明する.

$$
\begin{aligned}
K_{l o c} & =\|_{i=1}^{n} \sup C_{j}\left(Q_{i}\right) \\
& \leq \|_{i=1}^{n} Q_{i} \\
& =Q
\end{aligned}
$$

であり, 命題 4 より $K_{l o c}$ は $G$ に関して可制御であるか ら,

$$
\begin{aligned}
K_{l o c} & \leq \sup C(Q) \\
& =K
\end{aligned}
$$

が成り立つ.

逆に $K_{l o c} \geq K$ を証明する. 命題 3 より $T_{i}(K), i=$ $1,2, \cdots, n$, は $G_{i}$ に関して可制御である. また $K \leq Q$ より $T_{i}(K) \leq T_{i}(Q), i=1,2, \cdots, n$, である. さらに $\left(Q_{1}, Q_{2}, \cdots, Q_{n}\right)$ は $Q$ の生成集合であるから, 補題 3 よ り $T_{i}(Q) \leq Q_{i}, i=1,2, \cdots, n$, である. よって,

$$
T_{i}(K) \leq Q_{i}, \quad i=1,2, \cdots, n
$$

となり,

$$
T_{i}(K) \leq \sup C_{i}\left(Q_{i}\right), i=1,2, \cdots, n
$$

である.これにより

$$
\begin{aligned}
K_{l o c} & =\|_{i=1}^{n} \sup C_{i}\left(Q_{i}\right) \\
& \geq \|_{i=1}^{n} T_{i}(K)
\end{aligned}
$$

である. よって, 補題 A1 より $K \leq \|_{i=1}^{n} T_{i}(K)$ である から， $K_{l o c} \geq K$ が成り立つ. 